\title{
Unraveling the sources and transport of particulate organic matter in the temperate monsoonal rivers, northeast China
}

\author{
SEN XU, FUJUN YUE, HU DING AND SILIANG LI
}

Institute of Surface-Earth System Science, School of Earth System Science, Tianjin University

Presenting Author: xusen@tju.edu.cn

Particulate organic matter (POM) transported by river plays an important role in the carbon cycle and can also reflect much information about energy transport pathways and anthropogenic disturbances in riverine ecosystems. Organic carbon (OC) in particulate form accounts for nearly half of the annual OC export from continents to the ocean, with the terrestrial OC buried in marine sediments supporting the long term regulation of the Earth's climate. In order to shed light on the sources and transport of POM in the temperate monsoonal rivers (the Songhua and Liao Rivers), northeast China, $\mathrm{C} / \mathrm{N}$ elemental ratios and stable carbon and nitrogen isotopes $\left(\delta^{13} \mathrm{C}_{\mathrm{POC}}\right.$ and $\left.\delta^{15} \mathrm{~N}_{\mathrm{PON}}\right)$ were applied. In the Songhua and Liao Rivers, most of the suspended particulate matter (SPM) transport takes place during the wet season with large water fluxes, and up to $61 \%$ of SPM was exported in May and August in the Songhua River due to thawing process and increasing precipitation. Spatially, more than half of the SPM export of the Songhua River occurred in the downstream regions of Harbin due to increasing soil erosion. The results of source analyses using $\delta^{13} \mathrm{C}_{\mathrm{POC}}, \delta^{15} \mathrm{~N}_{\mathrm{PON}}$, and $\mathrm{C} / \mathrm{N}$ ratio indicate that POM of SPM in the wet season mainly originated from soil organic material. The estimated POC flux and yield of the Songhua River in 2010 were $3.45 \times 10^{5}$ tons $\mathrm{C}$ and $0.65 \mathrm{t} \mathrm{C}$ $\mathrm{km}^{-2}$, respectively. Under high SPM concentration condition, the SPM of the Songhua River has higher OM content than the average of the world largest rivers due to the organic matter-rich soil. The POC yield of the Songhua River was also larger than many other world largest rivers for a given SPM yield. Overall, these findings highlight the high sensitivity of the terrestrial OM export to erosion in northeast China. 